\title{
Three-Dimensional Conformal Radiotherapy with Concomitant Boost and Weekly Cisplatin in Muscle-Invasive Transitional Cell Bladder Carcinoma
}

\author{
NADA S. SHAMS EL-DIN, M.Sc.*; ASHRAF F. BARAKAT, M.D.*; MOHAMMED F. SHETA, M.D.* and \\ MOHAMMED H. RADWAN, M.D.**
}

The Departments of Clinical Oncology* and Urology**, Faculty of Medicine, Tanta University

\begin{abstract}
Background: Local control of MIBC by bladder-sparing approach is unsatisfactory. In order to improve the effectiveness of radiotherapy, we have designed a protocol that combines TURB with a non-conventionally fractionated radiotherapy "concomitant boost.
\end{abstract}

Aim of Study: To evaluate the response rate and toxicity criteria in patients with transitional cell bladder cancer treated with maximum Transurethral Resection (TUR), followed by 3-D conformal radiotherapy with a concomitant boost and weekly cisplatin with shortening of overall treatment time.

Patients and Methods: Between July 2017 to June 2018 20 patients with a T2-T3 NOM0 transitional cell carcinoma of the bladder underwent transurethral resection of bladder tumor as much as safely possible (maximum TURBT). They received radiotherapy delivered in short overall treatment time with a concomitant boost technique. With this technique, a dose of 40Gy in 2-Gy fractions was administered to the small pelvis with a concomitant boost limited to the bladder tumor area plus a margin of $15 \mathrm{~Gy}$ in fractions of $0.75 \mathrm{~Gy}$. The total tumor dose was 55Gy in 20 fractions in 4 weeks. Weekly Cisplatin $\left(30 \mathrm{mg} / \mathrm{m}^{2}\right)$ was administered weekly concurrently with radiotherapy. Cisplatin was interrupted in case of hematological or renal toxicity. The National Cancer Institute Common Toxicity Criteria, version 5, scale was used to assess the chemotherapy and acute radiation toxicity $\{$ Common Terminology Criteria for Adverse Events (CTCAE), Version 5.0, November 2017\}. We assessed late toxicity using The Radiation Therapy Oncology Group/The European Organization for Research and Treatment of Cancer (RTOG/EORTC) Late Radiation Morbidity Scoring Scheme.

Results: The feasibility of the treatment was good. Severe acute toxicity $>$ !G3 was observed in two patients (10\%). Severe late toxicity >! G3 was observed in one patient (5\%). Fourteen patients $(70 \%)$ showed a complete and three $(15 \%)$ a partial remission after treatment.

Conclusion: In external radiotherapy for muscle-invasive bladder cancer a concomitant boost technique coupling a

Correspondence to: Dr. Nada S. Shams El-Din, The Departments of Clinical Oncology, Faculty of Medicine, Tanta University partial bladder boost with shortening of the overall treatment time provides a high probability of local control with acceptable toxicity.

Key Words: CBAHRT (concomitant boost accelerated hyper fractionated radiotherapy) - Concomitant weekly cisplatin - Response rate - Acute and late toxicity criteria.

\section{Introduction}

BLADDER cancer is the tenth most common cancer and the 14 th most leading cause of cancer death worldwide in 2018. In Egypt; it is the $4^{\text {th }}$ most common cancer and the fifth most leading cause of cancer death in 2018. Given that the median age at diagnosis is 73 years, medical comorbidities are a frequent consideration in patient management [1,2].

The clinical spectrum of bladder cancer can be divided into 3 categories that differ in prognosis and management. The first category consists of non-muscle-invasive disease, for which treatment is directed at reducing recurrences and preventing progression to a more advanced stage [3]. The second group encompasses muscle-invasive disease. The goal of therapy is to determine whether the bladder should be removed or if it can be preserved without compromising survival. The critical concern for the third group, consisting of metastatic lesions, is how to prolong quantity and maintain the quality of life [4]. The most common presenting symptom in patients with bladder cancer is microscopic or gross hematuria, although urinary frequency from irritation or a reduced bladder capacity can also develop [5]. Patients presenting with these symptoms should be evaluated with cystoscopy to determine if a lesion is present. If one is documented, Transurethral Resection of the 
Bladder Tumor (TURBT) should be done to confirm the diagnosis and determine the extent of disease within the bladder while completely resecting all visible tumors. Therefore, an adequate sample that includes bladder muscle (i.e., muscularis propria) must be in the resection specimen [6].

The majority of muscle-invasive tumors are high-grade urothelial carcinomas. Further treatment following initial TURBT is often required [7] Different treatment modalities include radical cystectomy, partial cystectomy, neoadjuvant or adjuvant therapy, bladder-preserving approaches, and systemic therapy for advanced disease [8] Bladder-preserving approaches are reasonable alternatives to cystectomy for patients who are medically unfit for surgery and those seeking an alternative to radical cystectomy. These approaches include Maximal TURBT with concurrent chemoradiotherapy or radiotherapy alone for select patients [9]. In concomitant chemoradiotherapy approach after maximum TURBT, the overall tumor status should be reassessed 2 to 3 months after treatment. If no residual tumor is detected, observation is appropriate. If residual disease is present, surgical consolidation of bladder only residual disease or treatment as metastatic disease is appropriate. If residual disease is Tis, Ta, or T1, intravesical BCG may be considered [10,11]. After conventional radical RT, a Complete Response (CR) can be achieved in up to $56 \%$ of patients with muscle-invasive tumor [12], however; one-half of these responders subsequently develop recurrence within a short median latency time of 12 months, which indicates a fast proliferation of tumor cells [13].

Many studies have been performed with an attempt to obtain better efficacy of radiotherapy by escalation of total dose, use of non-conventional fractionation schemes [14], reduction of overall treatment time or combining external radiotherapy with interstitial brachytherapy [15]. In order to improve the effectiveness of treatment of muscleinvasive bladder cancer, our treatment protocol is designed to combine TURBT with a non-conventionally fractionated radiotherapy "concomitant boost" delivered over a shortened overall treatment time of 4 weeks with concurrent chemotherapy.

\section{Patients and Methods}

This prospective phase II study was carried out at Clinical Oncology Department and Urology Department at Tanta University Hospitals and included 20 patients with invasive transitional cell bladder cancer treated with maximum TURBT, accelerated hyper fractionated radiotherapy with concomitant boost and concurrent weekly cisplatin throughout the period from July 2017 to June 2018.

\section{Radiation therapy:}

For simulation, the bladder was drained of urine and filled with $30 \mathrm{~mL}$ of contrast medium and 10 to $30 \mathrm{~mL}$ of air. The rectum had to be as empty as possible [16]. During the first phase of treatment, the bladder was treated along with a margin of $1 \mathrm{~cm}$. In men, the prostate was also covered in this first phase because there might be occult stromal invasion or extension into the prostatic urethra. In women, the proximal $2 \mathrm{~cm}$ of the urethra was also considered a target. The internal and external iliac lymph nodes of the pelvis were also covered for this phase of therapy (RTOG 0926). Planning Target Volume (PTV) expansions of $1 \mathrm{~cm}$ around the bladder and bladder tumor were employed, with $0.7-\mathrm{cm}$ margins for prostate $(0.5-\mathrm{cm}$ posterior) and pelvic nodes (RTOG 0926) as shown in Fig. (1). PTV margins might be decreased a little when targets abutted large amounts of the low hanging small bowel. The boost phase of treatment included the tumor alone with a $1.5 \mathrm{~cm}$ margin.

All patients were treated with 3-D conformal radiotherapy in a dose of $40 \mathrm{~Gy}$ in 20 fractions to the whole pelvis (including the bladder, the total bladder tumor volume, the prostate and pelvic lymph nodes as Planning Target Volume [PTV 1]) within 4 weeks (20 2GY, once daily, 5 days/week) with concomitant boost limited to the bladder tumor area plus $1.5 \mathrm{~cm}$ margin or the whole bladder (PTV 2) with a dose of $15 \mathrm{~Gy}$ in 20 fractions, $0.75 \mathrm{~Gy} /$ fraction, 5 days/week as shown in Fig. (2). The mean overall treatment time was 27 days (23-30 days). The total tumor dose was $55 \mathrm{~Gy}$ in 20 days, in 4 weeks, delivered by high energy photons from a linear accelerator to ensure a homogeneous dose distribution. Maximum dose to the femoral heads should be limited to $45 \mathrm{~Gy}$. The volume of the femoral head receiving 50Gy was less than $10 \%$. The volume of the small and large bowel receiving $50 \mathrm{~Gy}$ was less than $5 \%$. The volume of the rectum receiving $30 \mathrm{~Gy}$ was less than $50 \%$. The dose to the non-involved bladder was maintained below 50Gy.

Weekly Cisplatin $\left(30 \mathrm{mg} / \mathrm{m}^{2}\right)$ was administered to the twenty patients. Complete blood cell counts and renal function tests were performed every week. Cisplatin was interrupted in case of hematological or renal toxicity [17]. 


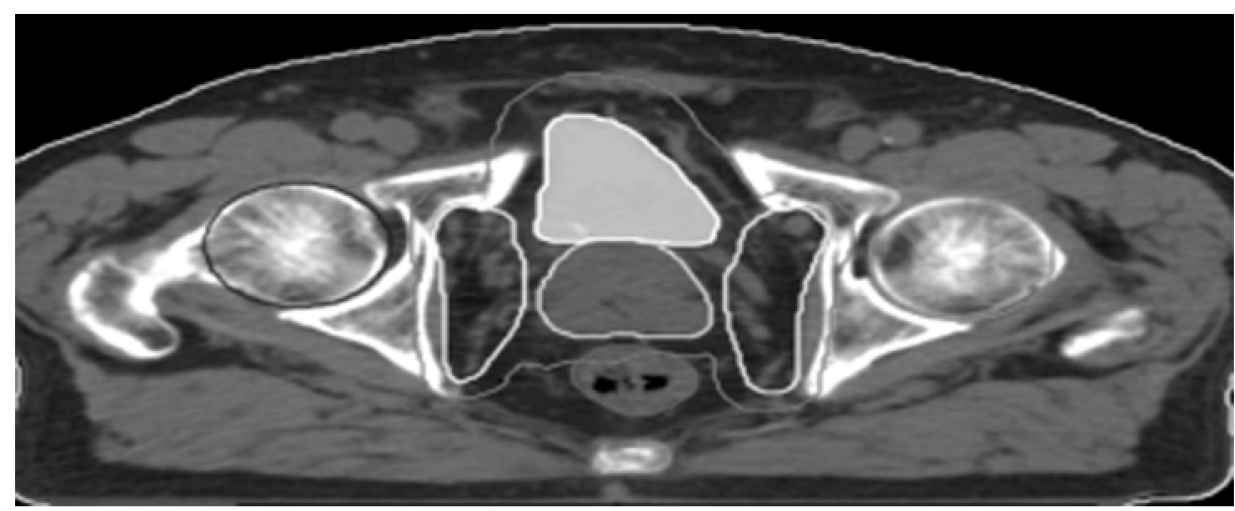

Fig. (1): PTV (red), CTV (green), GTV (yellow) during phase I.

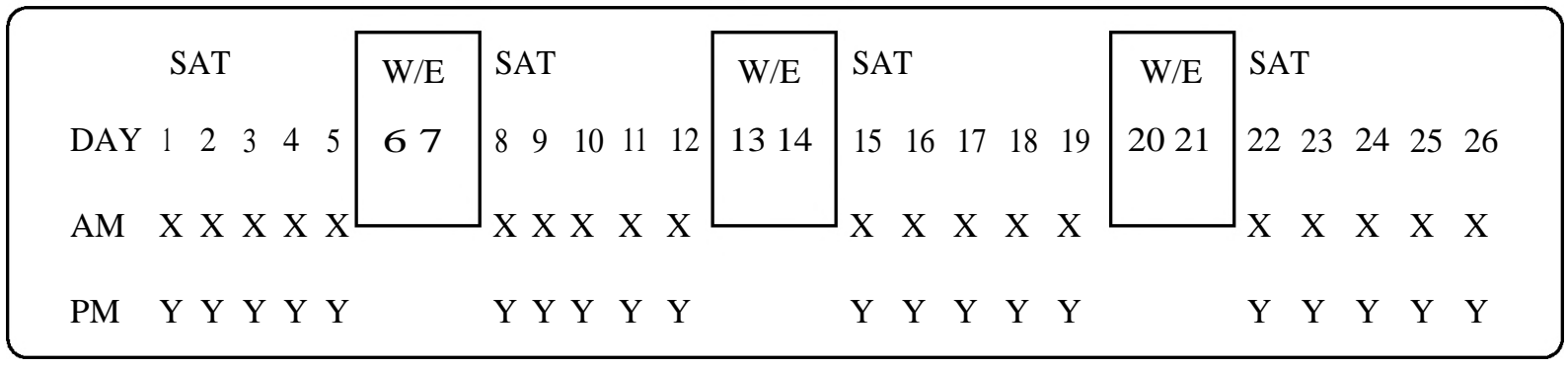

Fig. (2): Accelerated fractionation for bladder cancer schedule.

$\geq 6$ hrs. between fractions

$\mathrm{X}$ : $2 \mathrm{GY}$ in the morning (whole pelvis).

W/E: Weekend.

$\mathrm{Y}: 0.75 \mathrm{GY}$ in the afternoon (concomitant boost). SAT: Saturday.

\section{Follow-up:}

Tumor response was assessed by CT scan and/or MRI for all patients 4 weeks after the end of prescribed treatment ( 3 months and 6 months after diagnosis) to evaluate the radiological response. Cystoscopy and biopsy were performed for patients who achieved a complete radiological response to confirm the pathological response. A clinical Complete Response (CR) was defined as the complete disappearance of the intravesical lesion and normalization of the computed tomography findings. Pathological complete response is confirmed by cystoscopic biopsy in case of clinical complete response. A Partial Response (PR) was defined as a $50 \%$ decrease in the sum of the products of two perpendicular diameters of all measurable lesions for a minimum of 4 weeks with no increase of $25 \%$ in the size of any single lesion or the appearance of any new lesion within the irradiated field. Patients were considered to have Progressive Disease (PD) if any new lesion appeared, if the tumor size increased $25 \%$ greater than the pretreatment measurements, or in the case of deterioration in clinical status consistent with disease progression. Patients whose findings did not meet the criteria of CR, PR, or PD and who could be followed for at least 2 months were classified as having Stable Disease (SD) $[18,19]$.
Acute toxicity was scored as the maximum toxicity during treatment or the first 3 months following treatment. Late toxicity was scored as maximum toxicity occurring or persisting after 3 months following treatment. The National Cancer Institute Common Toxicity Criteria, version 5, scale was used to assess the chemotherapy and acute radiation toxicity $\{$ Common Terminology Criteria for Adverse Events (CTCAE), Version 5.0, November 2017$\}$. We assessed late toxicity using The Radiation Therapy Oncology Group/The European Organization for Research and Treatment of Cancer (RTOG/EORTC) Late Radiation Morbidity Scoring Scheme [20]

\section{Results}

\section{Patient characteristics:}

Twenty patients with invasive bladder cancer that had been histologically diagnosed received concomitant boost accelerated hyper fractionated radiotherapy. Most of them were patients who refused surgery or could not undergo surgical therapy due to age or comorbidity. As the first symptom; most patients $(90 \%)$ had dysuria and UTI. Patients and disease characteristics are shown in (Table 1). 
Table (1): Patient and disease characteristics.

\begin{tabular}{lll}
\hline & $\mathrm{N}$ & Percent \\
\hline Age (years): & \multicolumn{2}{c}{$40-80$} \\
Range & $59 \pm 11.32$ \\
Mean $\pm \mathrm{SD}$ & \multicolumn{2}{c}{} \\
Gender: & 17 & 85 \\
Male & 3 & 15 \\
Female & & \\
WHO PS: & 3 & 15 \\
0 & 17 & 85 \\
1 & & \\
Grade: & 12 & 60 \\
Low & 8 & 40 \\
High & & \\
Hydro nephrosis: & 16 & 80 \\
No & 4 & 20 \\
Yes & & \\
Stage: & 12 & 60 \\
T2 & 8 & 40 \\
T3 & & \\
Tumor site: & 13 & 65 \\
Focal & 7 & 35 \\
Diffuse & & \\
TUR: & 6 & 30 \\
Incomplete & 14 & 70.0 \\
Complete & & \\
& &
\end{tabular}

Response to therapy and failure pattern:

Treatment response evaluated after completing CBRT showed that Complete Response (CR) was achieved in 14 patients (70\%) with no evidence of the tumor by all investigations as shown in (Table 2). Partial Response (PR) was found in 3 patients $(15 \%)$. Stable Disease (SD) was observed in 2 patients (10\%). One (5\%) patient had Progressive Disease (PD). Locoregional control rate was $95 \%$. The Objective Response Rate (ORR) was $85 \%$.

Table (2): Evaluation of pattern of response $3 \& 6$ months after diagnosis in all 20 patients.

\begin{tabular}{lccccc}
\hline \multirow{2}{*}{$\begin{array}{l}\text { Response } \\
\text { pattern }\end{array}$} & \multicolumn{2}{c}{$\begin{array}{c}\text { 3 months } \\
\text { after diagnosis }\end{array}$} & & & \multicolumn{2}{c}{$\begin{array}{c}6 \text { months } \\
\text { after diagnosis }\end{array}$} \\
\cline { 2 - 3 } \cline { 5 - 6 } & Number of pts & Percent & & Number of pts & Percent \\
\hline CR & 14 & 70 & & 13 & 65 \\
PR & 3 & 15 & & 2 & 10 \\
SD & 2 & 10 & & 2 & 10 \\
PD & 1 & 5 & & 3 & 15 \\
ORR & 17 & 85 & & 15 & 75 \\
\hline
\end{tabular}

The median duration of follow-up was 10 (1$18)$ months. We used univariate analysis to analyze age ( $\leq 55$ yrs., $>55$ yrs.), grade (low, high), TUR (complete, incomplete), tumor pattern (focal, diffuse), sex (male, female), performance status ( 0 , 1), hydronephrosis (yes, no), and tumor stage (T2,
T3). By bivariable analysis, the prognostic factors for a CR at first cystoscopy were T stage $(p=0.009)$, tumor grade $(p=0.010)$, tumor multifocality ( $p=$ $0.05)$, TUR ( $p=0.019)$ and absence of hydronephrosis $(p=0.028)$.

Table (3): Response rate according to grade of disease.

\begin{tabular}{lllllllll}
\hline & \multicolumn{9}{c}{ Grade } \\
\cline { 2 - 9 } \begin{tabular}{l} 
Response $\begin{array}{l}\text { Late } \\
\text { rate }\end{array}$ \\
\cline { 2 - 10 }
\end{tabular} & \multicolumn{3}{c}{ Low } & \multicolumn{4}{c}{ High } & \multicolumn{2}{c}{$\begin{array}{c}\text { Fisher's } \\
\text { exact test }\end{array}$} \\
\cline { 2 - 10 } & $\mathrm{N}$ & $\%$ & Total N & $\%$ & Total & $\chi^{2}$ & $p$-value \\
\hline $\mathrm{CR}$ & 11 & 91.7 & 12 & 3 & 37.5 & 8 & 6.706 & $0.010^{*}$ \\
$\mathrm{PR}$ & 1 & 8.3 & 12 & 2 & 25.0 & 8 & 1.046 & 0.306 \\
ORR & 12 & 100.0 & 12 & 5 & 62.5 & 8 & 5.294 & $0.021^{*}$ \\
\hline
\end{tabular}

Table (4): Response rate according to hydronephrosis.

\begin{tabular}{llllllcccc}
\hline & \multicolumn{9}{c}{ Hydronephrosis } \\
\cline { 2 - 9 } $\begin{array}{l}\text { Response } \\
\text { pattern }\end{array}$ & \multicolumn{3}{c}{ No } & \multicolumn{4}{c}{ Yes } & \multicolumn{2}{c}{$\begin{array}{c}\text { Fisher's } \\
\text { exact test }\end{array}$} \\
\cline { 2 - 10 } & $\mathrm{N}$ & $\%$ & Total N & $\%$ & Total & $\chi^{2}$ & $p$-value \\
\hline CR & 13 & 81.3 & 16 & 1 & 25.0 & 4 & 4.821 & $0.028^{*}$ \\
PR & 1 & 6.3 & 16 & 2 & 50.0 & 4 & 4.804 & $0.026^{*}$ \\
ORR & 14 & 87.5 & 16 & 3 & 75.0 & 4 & 0.392 & 0.531
\end{tabular}

Table (5): Response rate according to TUR.

TUR

\begin{tabular}{|c|c|c|c|c|c|c|c|c|}
\hline \multirow{2}{*}{\multicolumn{2}{|c|}{$\begin{array}{l}\text { Response } \\
\text { pattern }\end{array}$}} & \multicolumn{2}{|c|}{ Incomplete } & \multicolumn{3}{|c|}{ Complete } & \multicolumn{2}{|c|}{$\begin{array}{l}\text { Fisher's } \\
\text { exact test }\end{array}$} \\
\hline & & $\%$ & Total & $\mathrm{N}$ & $\%$ & Total & $x^{2}$ & $p$-value \\
\hline CR & 2 & 33.3 & 6 & 12 & 85.7 & 14 & 5.488 & $0.019 *$ \\
\hline PR & 2 & 33.3 & 6 & 1 & 7.1 & 14 & 2.260 & 0.133 \\
\hline ORR & 4 & 66.7 & 6 & 13 & 92.9 & 14 & 2.260 & 0.133 \\
\hline
\end{tabular}

Table (6): Response rate according to $\mathrm{T}$ stage.

T Stage

\begin{tabular}{|c|c|c|c|c|c|c|c|c|}
\hline \multirow[t]{2}{*}{$\begin{array}{l}\text { Response } \\
\text { pattern }\end{array}$} & \multicolumn{3}{|c|}{ Stage 2} & \multicolumn{3}{|c|}{ Stage 3} & \multicolumn{2}{|c|}{$\begin{array}{l}\text { Fisher's } \\
\text { exact test }\end{array}$} \\
\hline & $\mathrm{N}$ & $\%$ & Total & $\mathrm{N}$ & $\%$ & Total & $x^{2}$ & $p$-value \\
\hline CR & 10 & 83.3 & 12 & 2 & 25.0 & & 806 & $0.009 *$ \\
\hline PR & 2 & 16.7 & 12 & 1 & 12.5 & 80 & 065 & 0.798 \\
\hline ORR & 12 & 100.0 & 12 & 3 & 37.5 & 81 & .000 & $0.002 *$ \\
\hline
\end{tabular}

Table (7): Response rate according to gender.

$$
\text { Gender }
$$

\begin{tabular}{|c|c|c|c|c|c|c|c|c|}
\hline \multirow[t]{2}{*}{$\begin{array}{l}\text { Response } \\
\text { pattern }\end{array}$} & \multicolumn{3}{|c|}{ Female } & \multicolumn{3}{|c|}{ Male } & \multicolumn{2}{|c|}{$\begin{array}{l}\text { Fisher's } \\
\text { exact test }\end{array}$} \\
\hline & $\mathrm{N}$ & $\%$ & Total & $\mathrm{N}$ & $\%$ & Total & $\chi^{2}$ & $p$-value \\
\hline CR & 2 & 66.7 & 3 & 12 & 70.6 & 17 & 0.019 & 0.891 \\
\hline PR & 1 & 33.3 & 3 & 2 & 11.8 & 17 & 0.930 & 0.335 \\
\hline ORR & 3 & 100.0 & 3 & 14 & 82.4 & 17 & 0.623 & 0.430 \\
\hline
\end{tabular}


Table (8): Response rate according to tumor site.

\begin{tabular}{lllllllll}
\hline & \multicolumn{4}{c}{ Tumor site } \\
\cline { 2 - 10 } $\begin{array}{l}\text { Response } \\
\text { pattern }\end{array}$ & \multicolumn{3}{c}{ Focal } & \multicolumn{3}{c}{ Diffuse } & \multicolumn{2}{c}{$\begin{array}{c}\text { Fisher's } \\
\text { exact test }\end{array}$} \\
\cline { 2 - 10 } & $\mathrm{N}$ & $\%$ & Total N & $\%$ & Total & $x^{2}$ & $p$-value \\
\hline CR & 11 & 84.6 & 13 & 3 & 42.9 & 7 & 3.778 & $0.050^{*}$ \\
PR & 2 & 15.4 & 13 & 1 & 14.3 & 7 & 0.004 & 0.948 \\
ORR & 13 & 100.0 & 13 & 4 & 57.1 & 7 & 6.555 & $0.010^{*}$ \\
\hline
\end{tabular}

Table (9): Response rate according to age.

\begin{tabular}{lccccccccc}
\hline & \multicolumn{9}{c}{ Age } \\
\cline { 2 - 10 } $\begin{array}{l}\text { Response } \\
\text { pattern }\end{array}$ & & \multicolumn{1}{c}{$\leq 55$} & & & $>55$ & & \multicolumn{2}{c}{$\begin{array}{c}\text { Fisher's } \\
\text { exact test }\end{array}$} \\
\cline { 2 - 10 } & $\mathrm{N}$ & $\%$ & Total & $\mathrm{N}$ & $\%$ & Total & $\chi^{2}$ & $p$-value \\
\hline CR & 5 & 71.4 & 7 & 9 & 69.2 & 13 & 0.010 & 0.919 \\
PR & 2 & 28.6 & 7 & 1 & 7.7 & 13 & 1.556 & 0.212 \\
ORR & 7 & 100.0 & 7 & 10 & 76.9 & 13 & 1.900 & 0.168 \\
\hline
\end{tabular}

Table (10): Response rate according to performance status.

\begin{tabular}{lcccccccc}
\hline & \multicolumn{1}{c}{ PS } \\
\cline { 2 - 9 } $\begin{array}{l}\text { Response } \\
\text { pattern }\end{array}$ & & 0 & & & 1 & & \multicolumn{2}{c}{$\begin{array}{c}\text { Fisher's } \\
\text { exact test }\end{array}$} \\
\cline { 2 - 10 } & $\mathrm{N}$ & $\%$ & Total & $\mathrm{N}$ & $\%$ & Total & $x^{2}$ & $p$-value \\
\hline CR & 2 & 66.7 & 3 & 12 & 70.6 & 17 & 0.019 & 0.891 \\
PR & 1 & 33.3 & 3 & 2 & 11.8 & 17 & 0.930 & 0.335 \\
ORR & 3 & 100.0 & 3 & 14 & 82.4 & 17 & 0.623 & 0.430 \\
\hline
\end{tabular}

By multivariate analysis, $\mathrm{T}$ stage $(p=0.022)$ and tumor grade $(p=0.017)$ were revealed to be independently related to response as shown in (Table 11).

Table (11): Multi variate analysis of prognostic factors for complete response.

\begin{tabular}{|c|c|c|c|c|c|}
\hline \multirow[b]{2}{*}{ Coefficients } & \multirow{2}{*}{$\begin{array}{l}\text { Odds } \\
\text { Ratio }\end{array}$} & \multicolumn{2}{|c|}{$95 \%$ CI } & \multirow[b]{2}{*}{$t$} & \multirow{2}{*}{$\begin{array}{c}\text { Sig. } \\
(p \text {-value })\end{array}$} \\
\hline & & $\begin{array}{l}\text { Lower } \\
\text { Bound }\end{array}$ & $\begin{array}{l}\text { Upper } \\
\text { Bound }\end{array}$ & & \\
\hline Grade & 0.46 & 0.09 & 0.82 & 2.696 & $0.017 *$ \\
\hline Hydronephrosis & 0.37 & 0.33 & 0.42 & 0.238 & 0.815 \\
\hline tumor site & 0.21 & 0.12 & 0.54 & 1.345 & 0.200 \\
\hline Stage & 0.38 & 0.06 & 0.69 & 2.579 & $0.022 *$ \\
\hline TUR & 0.25 & 0.18 & 0.68 & 1.243 & 0.234 \\
\hline
\end{tabular}

Dependent Variable: CR.

\section{Acute toxicity:}

Severe and life-threatening acute toxicity was extremely rare; however, Grade I \& II GU and GI toxicity was experienced by most of the patients. No acute or late skin toxicities were observed in the patients. Acute bowel and urinary toxicity were observed in $13(65 \%)$ and $15(75 \%)$ of the patients, respectively.

All but four patients $(80 \%)$ completed the planned radiotherapy without interruptions. For Grade III acute colitis or any other Grade III in field (radiation-related) toxicity during any treatment week (such as radiation cystitis), RT was delayed until resolution of the toxicity to Grade 2 or less. For the four patients, treatment was interrupted at $35.8 \mathrm{~Gy}$ (range $27.5-44 \mathrm{~Gy}$ ) because of severe diarrhea, dehydration and severe dysuria (Grade III Toxicity) requiring hospitalization, antibiotic and intravenous fluid administration. The overall schedule was protracted by 3 to 5 days until the regression of diarrhea and cystitis. Acute bowel toxicity was observed in 13 patients $(65 \%)$. It can be seen that most of them encountered Grade I toxicity $(\mathrm{n}=10,50 \%)$ or Grade II toxicity $(\mathrm{n}=2$, $10 \%$ ), and no serious acute toxicity was observed. Acute bladder toxicity was observed in 15 patients (75\%). Grade I \& II toxicities were observed in $10(50 \%)$ and $4(20 \%)$ patients respectively. One patient $(5 \%)$ had frequency, cystitis, dysuria, nocturia less than hourly and/or pain requiring strong analgesics (Grade 3 toxicity) as shown in (Table 12). The symptoms persisted for nearly 6 months but were eventually relieved with an antispasmodic agent.

Weekly cisplatin was successfully delivered in all 20 patients. Cisplatin was interrupted in four patients during treatment due to hematological and nephrotoxicity. These patients received intravenous fluids, blood, and growth factors so that they continued concurrent chemoradiotherapy.

Table (12): Acute skin, urinary, and gastrointestinal toxicity according to CTCAE V5.0.

\begin{tabular}{lccccc}
\hline \multicolumn{5}{c}{ Grade (N) } \\
\hline Events & I & II & III & IV V \\
\hline - Skin & $10(50 \%)$ & $2(10 \%)$ & & - & - \\
- Gastrointestinal \\
$\begin{array}{l}\text { (diarrhea, vomiting) } \\
\text { - Urinary toxicity } \\
\begin{array}{l}\text { (urgency, frequency, } \\
\text { dysuria) }\end{array}\end{array}$ & $10(50 \%)$ & $2(10 \%)$ & $1(5 \%)$ & - & - \\
\hline
\end{tabular}

\section{Chronic toxicity:}

Chronic genitourinary and gastrointestinal toxicity was evaluated 6 months following treatment. Grade 0, I \& II genitourinary late toxicity occurred in $11 / 20(55 \%), 6 / 20(30 \%)$ and $2 / 20(10 \%)$ patients respectively. One patient (5\%) experienced severe frequency and dysuria with frequent hematuria (Grade 3 late toxicity). Late gastrointestinal toxicity 
grade I and II were observed in $3 / 20(15 \%)$ and $2 / 20(10 \%)$ patients, respectively. One patient developed GIII bowel toxicity. No severe Grade $>$ III late bladder or bowel toxicity was observed as shown in (Table 13).

Table (13): Late urinary, gastrointestinal toxicity according to RTOG/EORTC scoring system.

\begin{tabular}{llllllll}
\hline \multicolumn{1}{c}{ Grade $(\mathrm{N})$} & & & & & \\
\hline Events & 0 & I & II & III & IV \\
\hline - Urinary toxicity (urgency, frequency, & 11 & 6 & 2 & 1 & - \\
$\begin{array}{l}\text { dysuria, hematuria) } \\
\text { - Gastrointestinal toxicity (abdominal pain, } \\
\text { diarrhea) }\end{array}$ & 14 & 3 & 2 & 1 & - \\
\hline
\end{tabular}

\section{Discussion}

Invasive bladder cancer presents two distinct problems from the outset. On the one hand, radical resection of the primary tumor is highly successful but carries a considerable impact on the quality of life. On the other hand, progression most frequently occurs outside the pelvis, likely owing to a high incidence of micrometastases at presentation [21] Radical cystectomy is associated with a 5-year disease-free survival rate ranging from $27-55 \%$. This outcome is significantly worse when reporting upon locally advanced cases. The independent prognostic factors include: Tumor stage, grade, pelvic nodal involvement and some other additional factors [22].

The published outcomes of patients treated with RT alone have been disappointing, with survival rates inferior to cystectomy. If radiation is used alone, long-term local control rates of around 30\% to $40 \%$ have historically been reported. Additionally, one-half of these responders subsequently develop local recurrence within a short median latency time of 12 months, indicating a fast proliferation of tumor clonogens [23]. Multimodality organ sparing studies, including radical TUR, systemic CT, and RT have been used with the intention of increasing local tumor response translating into high rates of OS, coupled with preservation of a well-functioning natural bladder. A growing number of studies have reported the use of chemotherapy concurrently with RT such that chemoradiation is rapidly becoming the standard of care for organ conservation approaches $[24,25]$ Overall survival rate in trimodality treatment for bladder cancer ranged from 39 to $63 \%$. The rate of recurrence following bladder preservation is reported to be $28-60 \%$ and salvage cystectomy is eventually required in $24-45 \%$ of patient. Survival rates at 5 years following salvage cystectomy are approximately $40 \%$ with a slightly higher risk of morbidity compared with non-irradiated cystectomy [26].

Evidence is increasing that rapidly proliferating tumors undergo accelerated clonogen repopulation during a lengthy course of RT and that this phenomenon is an important cause of local failure in treatment involving conventional fractionation schedules. It has been suggested that a reduction in the overall treatment time for RT is a reasonable strategy to minimize the clonogenic tumor repopulation and improve the quality of life, which is important with respect to the median age of patients suffering from bladder cancer. However, an increase in the dose per fraction increases late side effects. Another method to minimize this repopulation is to decrease the daily fractionation dose and to perform fractionations more frequently [27]. Accelerated Fractionation (AF) is a method to reduce the overall treatment time without a significant increase in individual fraction size and is usually based on the administration of more than one fraction per day. The hypothesis is that accelerated fractionation has an increased antitumor effect by reducing the time available for repopulation during the overall course of radiotherapy without leading to an increase in the risk of late normal tissue damage as fraction sizes are kept small, or of acute toxicity because of the early treatment gap [28]

Several prospective randomized trials in respiratory tract tumors have shown that accelerated RT protocols delivering the same total dose in a shorter interval than with standard fractionation can improve local control and even survival [29] The same phenomenon may be applied to transitional-cell bladder carcinomas as well. Tumor clonogenic repopulation in bladder tumors accelerates after a lag period of 5 to 6 weeks from the start of treatment and a dose increment of 0.36 Gy/day is required to compensate for this repopulation. RT for bladder cancer should be completed in less than 5 weeks (acceleration may counteract repopulation). The concomitant boost RT technique study by Piet et al., was performed with 92 elderly patients who underwent fractionated RT 5 days per week for 4 weeks. A total of $55 \mathrm{~Gy}$ was administered. The bladder and pelvic lymph nodes were irradiated to a dose of $40 \mathrm{~Gy}$ in daily fractions of 2 Gy for 4 weeks combined with a daily concomitant boost of $0.75 \mathrm{~Gy}$ in the same treatment sessions. In that study, the CR rate was $78 \%$ and the 3 -year OS rate was $36 \%$ [30].

In the present study, pelvic tumor control rate of $(19 / 20 ; 95 \%)$ observed in our study seems logical 
when taking into account that most patients (70\%) underwent complete TURBT before entering the study. However, considering the relatively high rates of advanced age (50\% were 60 years), locally advanced tumor stages (40\% had T3), and tumorrelated ureter obstruction (20\%), bladder function is indeed well preserved. The overall outcome, however, does not appear to be improved in comparison with the similar previously mentioned studies $[14,30]$.

The main potential drawback of accelerated radiotherapy is the increased risk of acute or late toxicity, possibly impairing the patients' quality of life. Acute bowel and urinary toxicity during accelerated hyper fractionated radiotherapy with concomitant boost for invasive bladder cancer were observed in $74-95 \%$ and $74-91 \%$ of the patients, respectively [13]. A single-arm study of 50 patients with localized bladder cancer used a dose of $40 \mathrm{~Gy} / 20$ fractions to the bladder with a $15 \mathrm{~Gy} / 20$ fractions concomitant boost to the tumor with a margin. The overall dose was 55Gy in 4 weeks. The treatment was well tolerated, with a urinary toxicity incidence of $14 \%$ and $13 \%$ for early and late grade 3 urinary toxicity, respectively [14]. Prior results with combined-modality therapy showed late GU and GI toxicity rates at $14 \%$ and $21 \%$, respectively [31]. A hypofractionated RT study was performed with 24 elderly patients who underwent $50 \mathrm{~Gy}$ in 20 fractions, with a CR of $83 \%$. In that study, acute grade 3GI or GU toxicities occurred in only $4 \%$ of the patients, acute grade 3 or 4 hematologic toxicity, liver toxicity, or both were experienced by $17 \%$ of the cohort and late grade 3 or 4 toxicity occurred in $9 \%$ in the patients [15]

In our study, the patients' pelvic tissues tolerated RT remarkably well, regardless of age and/or another condition. The rates of serious acute and late toxicities in our series were comparable to those of conventional RT series. We observed acute bowel and urinary toxicity, mostly grade 2, in $85 \%$ and $90 \%$, respectively. Only two patients presented with transient grade III acute small bowel toxicity. Two patients presented with grade III acute urinary toxicity. Severe late effects were also moderate, with no patients presenting more than grade III toxicity. One patient encountered severe late bowel and urinary toxicity; this might have been influenced by the dose of 40Gy delivered to the entire small pelvis. We were concerned that more intensive therapy would result in impaired late bladder function. However, late toxicity, as measured with the use of RTOG showed no significant increase in late toxicity.

\section{Conclusion:}

The present study shows that treating invasive bladder cancer by transurethral resection and accelerated hyper fractionated radiotherapy with concomitant boost, with or without concurrent cisplatin provides a high probability of local and distal control with acceptable toxicity in properly selected patients who are unwilling or unfit to undergo radical cystectomy and also has the advantage of reducing by 2 weeks the overall treatment time compared with standard radiotherapy. It also has the advantage of reducing cost due to shortening of overall treatment time.

\section{References}

1- BRAY F., FERLAY J., SOERJOMATARAM I., et al.: Global Cancer Statistics: GLOBOCAN Estimates of Incidence and Mortality Worldwide for 36 Cancers in 185 Countries. CA Cancer J. Clin., 2018.

2- FERLAY J., ERVIK M., LAM F., et al.: Global Cancer Observatory: Cancer Today. Lyon, France: International Agency for Research on Cancer, 2018.

3- SYLVESTER R.J., VAN DER MEIJDEN A.P., OOSTERLINCK W., et al.: Predicting recurrence and progression in individual patients with stage Ta T1 bladder cancer using EORTC risk tables: a combined analysis of 2596 patients from seven EORTC trials. Eur. Urol., 49: 466465,2006

4- HAYTER C.R., PASZAT L.F., GROOME P.A., et al.: The management and outcome of bladder carcinoma in Ontario, 1982-1994. Cancer, 89: 142-51, 2000.

5- KHADRA M.H., PICKARD R.S., CHARLTON M., et al.: A prospective analysis of 1,930 patients with hematuria to evaluate current diagnostic practice. J. Urol., 163: 5247, 2000.

6- ALFRED W.J., LEBRET T., COMPÉRAT E.M., et al. Updated 2016 EAU Guidelines on Muscle-invasive and Metastatic Bladder Cancer. European Urology, 71: 46275, 2017.

7- LEIBOVICI D., KASSOUF W., PISTERS L.L., et al.: Organ preservation for muscle-invasive bladder cancer by transurethral resection. Urology, 70: 473-6, 2007.

8- GAKIS G., EFSTATHIOU J., LERNER S.P., et al.: ICUDEAU International Consultation on Bladder Cancer 2012: Radical cystectomy and bladder preservation for muscleinvasive urothelial carcinoma of the bladder. Eur. Urol. 63: 57, 2013.

9- PLOUSSARD G., DANESHMAND S., EFSTATHIOU J.A., et al.: Critical analysis of bladder sparing with trimodal therapy in muscle-invasive bladder cancer: A systematic review. Eur. Urol., 66: 120-37, 2004.

10-ZAPATERO A., MARTIN De VIDALES C., ARELLANO R., et al.: Updated results of bladder-sparing trimodality approach for invasive bladder cancer. Urol. Oncol., 28: 368-74, 2010

11-KAUFMAN D.S., WINTER K.A., SHIPLEY W.U., et al.: The initial results in muscle-invading bladder cancer of RTOG 95-06: Phase I/II trial of transurethral surgery plus 
radiation therapy with concurrent cisplatin and 5flourouracil followed by selective bladder preservation or cystectomy depending on the initial response. Oncologist, 5: 471-6, 2000.

12-BORGAONKAR S., JAIN A., BOLLINA P., et al.: Radical radiotherapy and salvage cystectomy as the primary management of transitional cell carcinoma of the bladder. Results following the introduction of a CT planning technique. Clin. Oncol., 14: 141-7, 2002.

13- YAVUZ A.A., YAVUZ M.N., OZGUR G.K., et al.: Accelerated superfractionated radiotherapy with concomitant boost for invasive bladder cancer. Int. J. Radiat. Oncol. Biol. Phys., 56: 745, 2003.

14- POS F.J., VAN TIENHOVEN G., HULSHOF M.C., et al.: Concomitant boost radiotherapy for muscle invasive bladder cancer. Radiother. Oncol., 68: 75-80, 2003.

15- PIET A.H., HULSHOF M.C., PIETERS B.R., et al.: Clinical results of a concomitant boost radiotherapy technique for muscle-invasive bladder cancer. Strahlenther Onkol., 184: 313-8, 2008.

16- CLARK P.E., AGARWAL N., BIAGIOLI M.C., et al.: National Comprehensive Cancer Network (NCCN). Bladder cancer. J. Natl. Compr. Canc. Netw., 11: 446-75, 2013.

17- National Comprehensive Cancer Network (NCCN). NCCN Clinical practice guidelines in oncology, 2017.

18- EISENHAUER E., THERASSE P., BOGAERTS J., et al.: New response evaluation criteria in solid tumors: Revised RECIST guideline (version 1.1). Eur. J. Cancer, 45: 228, 2009.

19- SCHWARTZ, LITIÈRE, ELISABETH, et al.: RECIST 1.Update and clarification: From the RECIST committee. European journal of cancer (Oxford, England: 1990), 62: 132,2016

20- COX J., STETZ J., PAJAK T., et al.: Toxicity criteria of the Radiation Therapy Oncology Group (RTOG) and the European Organization for Research and Treatment of Cancer (EORTC). Int. J. Radiat. Oncol. Biol. Phys., 31: $1341,1995$.

21- ALDOUSARI S. and KASSOUF W.: Update on the management of muscle invasive bladder cancer. Canadian Urological Association Journal, 4: 56-64, 2010.
22- ZAGHLOUL, MOHAMED SAAD, ADJUVANT and neoadjuvant radiotherapy for bladder cancer. Future oncology (London, England), 6: 1177-91, 2010.

23- RENE N.J., CURY F.B. and SOUHAMI L.: Conservative treatment of invasive bladder cancer. Curr. Oncol., 16: 47, 2009.

24- KAUFMAN D.S., WINTER K.A., SHIPLEY W.U., et al.: Phase I-II RTOG study (99-06) of patients with muscleinvasive bladder cancer undergoing transurethral surgery, paclitaxel, cisplatin, and twice daily radiotherapy followed by selective bladder preservation or radical cystectomy and adjuvant chemotherapy. Urology, 73: 833-7, 2009.

25- SABAA M.A., EL-GAMAL O.M., ABO-ELENEN M., et al.: Combined modality treatment with bladder preservation for muscle invasive bladder cancer. Urol. Oncol., 28: 14-20, 2010.

26- ZAGHLOUL, MOHAMED S., and MOUSA AMR G.: Trimodality treatment for bladder cancer: Does modern radiotherapy improve the end results? Expert review of anticancer therapy, 10: 1933-44, 2010.

27- CANYILMAZ EMINE, YAVUZ MELEK NUR, SERDAR LASIF, et al.: Long-term outcomes in treatment of invasive bladder cancer with concomitant boost and accelerated hyperfractionated radiation therapy. International journal of radiation oncology, biology, physics, 90: 562-9, 2014.

28- VISWANATHAN A.N., YORKE E.D., MARKS L.B., et al.: Radiation dose-volume effects of the urinary bladder. Int. J. Radiat. Oncol. Biol. Phys., 76: S22, 2010.

29- FU K.K., PAJAK T.F., TROTTI A., et al.: A Radiation Therapy Oncology Group (RTOG) phase III randomized study to compare hyperfractionation and two variants of accelerated fractionation to standard fractionation radiotherapy for head and neck squamous cell carcinomas: First report of RTOG 9003. Int. J. Radiat. Oncol. Bio. Phys., 48: 7, 2000.

30- TURGEON G.A., SOUHAMI L., CURY F.L., et al.: Hypofractionated intensity-modulated radiation therapy in combined modality treatment for bladder preservation in elderly patients with invasive bladder cancer. Int. J. Radiat. Oncol. Biol. Phys., 88: 326-31, 2014.

31- GOFFIN J.R., RAJAN R. and SOUHAMI L.: Tolerance of radiotherapy and chemotherapy in elderly patients with bladder cancer. Am. J. Clin. Oncol., 27: 172-7, 2004. 


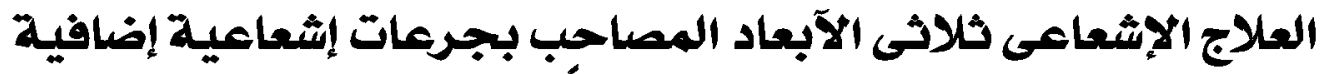

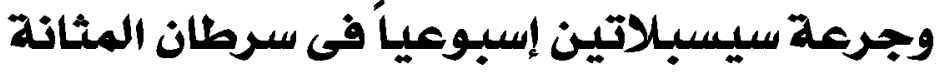

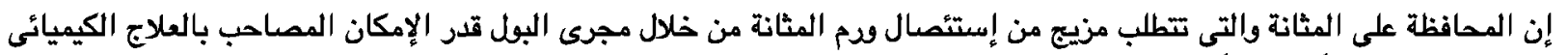

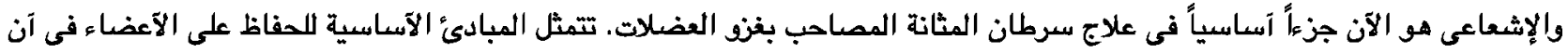

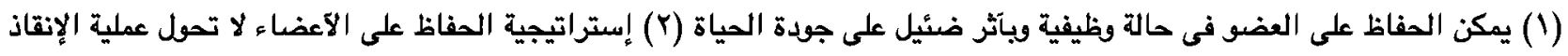

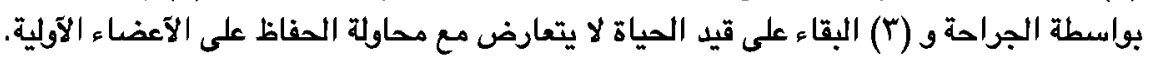

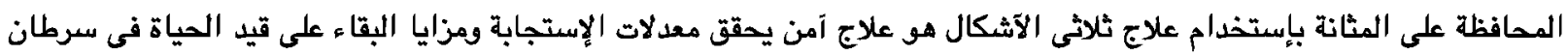

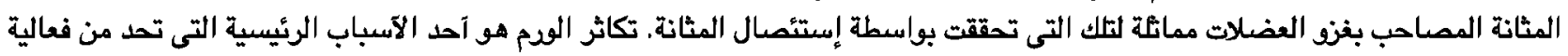

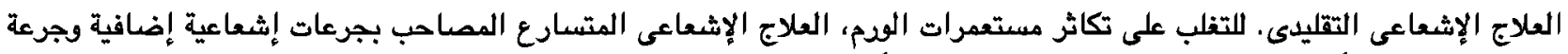

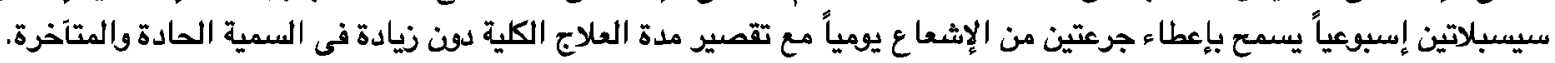

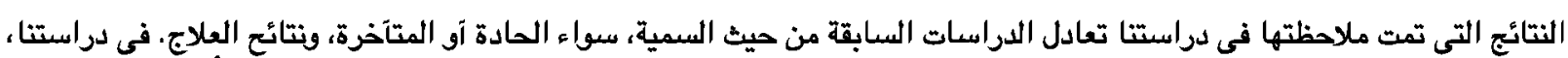

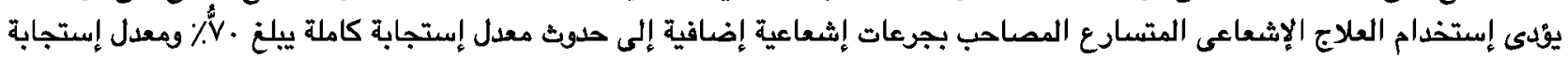

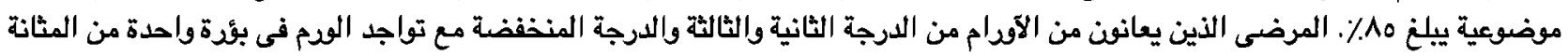

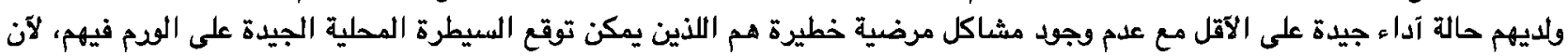

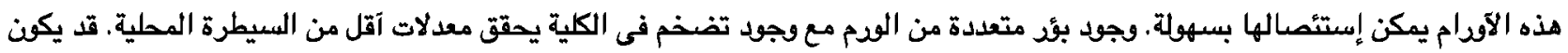
من الآفضل علاج هؤلاء المرضى بواسطة الإستئصال الجذرى المثانة.

يبدور التعاون الوثيق بين جراحى المسالك البولية، والآخصائيين فى علم الآمراض، وآطباء الآودام بالإشعاع، وآطباء الآدرام الطيييين آكثر

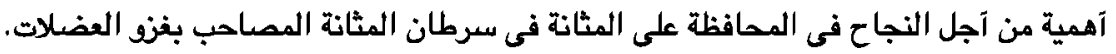

